\title{
Correlation of Levels of Folded Recombinant p53 in Escherichia coli with Thermodynamic Stability in Vitro
}

\author{
Sebastian Mayer, Stefan Rüdiger, Hwee Ching Ang \\ Andreas C. Joerger and Alan R. Fersht*
}

\author{
Cambridge University \\ Chemical Laboratory and \\ Cambridge Centre for Protein \\ Engineering, MRC Centre \\ Hills Road, Cambridge \\ CB2 0QH, UK
}

\begin{abstract}
The amount of folded functional protein in a cell is controlled by a number of factors, including the relative rates of its biosynthetic and specific degradation processes, and its intrinsic thermodynamic stability. Mutationinduced loss of stability is a common cause of disease. Many oncogenic mutants of the tumour suppressor p53, for example, reduce the intrinsic thermodynamic stability of the protein in vitro. We have analysed the level of recombinant folded human p53 core domain (p53C) and its mutants in Escherichia coli spanning a stability range of $6 \mathrm{kcal} / \mathrm{mol}$ to assess the effects of intrinsic thermodynamic stability in vivo in the absence of specific ubiquitin-mediated pathways in human cells. The levels of folded protein were measured fluorimetrically in living cells by fusing the gene of p53C upstream to that of green fluorescent protein and measuring the fluorescence relative to a control at various temperatures. At a fixed temperature, the amount of fluorescence is correlated with the thermodynamic stability of the mutant. The level of each protein varied with temperature according to a sigmoid curve that paralleled the melting in vitro, but the apparent $T_{\mathrm{m}}$ was lower in vivo, because steady-state levels are observed rather than true thermodynamic equilibria. Our results show clearly that changes in the intrinsic thermodynamic stability of p53 reduce the level of folded and hence functional p53 substantially in E. coli, and provide insights into the correlation between protein instability and disease at the cellular level.
\end{abstract}

(C) 2007 Elsevier Ltd. All rights reserved.

\section{Introduction}

Does the thermodynamic stability of a protein determine its fate in the cell? Early protein engineering studies showed that proteins have not necessa-

Present address: S. Rüdiger, Cellular Protein Chemistry, Utrecht-University, Padualaan 8, 3584 CH Utrecht, The Netherlands.

Abbreviations used: EGFP, enhanced green fluorescent protein; RFU, relative fluorescent units; p53C, wild-type p53 core domain; T-p53C, thermostable mutant of p53 core domain containing the four point mutations M133L, V203A, N239Y, and N268D; $T_{\mathrm{m}}$, melting temperature $\left({ }^{\circ} \mathrm{C}\right)$; DSC, differential scanning calorimetry.

E-mail address of the corresponding author: arf25@cam.ac.uk rily evolved to maximum stability. ${ }^{1,2}$ Certain proteins may have to be sufficiently unstable for their levels and location to be regulated. Degradation, trafficking by unfolding and refolding reactions assisted by chaperones, and proteolysis may well require a certain degree of instability, ${ }^{3}$ and some proteins may be on the verge of instability. Even relatively small mutation-induced changes of the thermodynamic stability of a protein may, therefore, have profound biological consequences, as in the case of the tumour suppressor protein p53, which is inactivated by mutation in about half of all human cancers. $^{4-6}$

The effects of mutations on thermodynamic stability in vitro are well documented. ${ }^{7}$ Although several elegant studies revealed aspects of protein stability in vivo, ${ }^{8-11}$ we still do not fully understand how the reversible unfolding of proteins in the testtube relates to the environment of the cell. There are 
effects of molecular crowding, ${ }^{12,13}$ molecular chaperones, ${ }^{14,15}$ and proteolytic degradation. ${ }^{16}$ Macromolecular crowding may increase protein stability by energetically favouring the compact folded versus the loose denatured state and favour the association of macromolecules, thereby increasing aggregation tendencies. ${ }^{13,17-20}$ Above all, the level of a protein in a cell may not reflect its thermodynamic stability because its concentration is in the steady state, which is in a balance between its rate of biosynthesis and rate of decay, the latter being a function of spontaneous denaturation and aggregation as well as specific biological processes such as targeted proteolysis. However, thermodynamic stability may well be a contributing factor.

p53 is a tetrameric multi-domain transcription factor that regulates several cellular processes. ${ }^{24}$ It consists of a natively unfolded N-terminal domain, ${ }^{25}$ a folded DNA-binding core domain (p53C), ${ }^{26}$ a folded tetramerization domain, ${ }^{27}$ and a natively unfolded C-terminal domain. ${ }^{28-30}$ The overall stability of the protein is dictated by its DNA-binding core domain, ${ }^{31}$ the equilibrium folding-unfolding transition of which fits to an apparent two-state model. ${ }^{32}$ Most cancer-associated p53 mutations are found in this domain. ${ }^{33}$ These mutations have been classified in vitro according to their DNA-binding and thermodynamic stability properties. ${ }^{34}$ A large number of cancer mutations reduce the thermodynamic stability of the core domain, resulting in local distortions or global unfolding. ${ }^{4,32}$ The classic temperature-sensitive mutant V143A, for instance, is destabilized by more than $3 \mathrm{kcal} / \mathrm{mol}$ in vitro. Conversely, the engineered thermostable quadruple mutant M133L/V203A/N239Y/N268D (T-p53C), which retains the overall structural and functional features of the wild-type, is stabilized by $2.5 \mathrm{kcal} / \mathrm{mol}^{35,36}$

The level of p53 in human cells has contributions from specific degradation pathways (via ubiquitination and proteosomal degradation) and from its inherent instability. ${ }^{37-39}$ By using Escherichia coli, it is possible to isolate the effects of inherent instability, which we believe may be an important factor, especially as we have recently shown that Nature has made p53 to be deliberately unstable by having unfulfilled buried hydrogen bond donors and acceptors. ${ }^{6}$ We developed a bacterial system to monitor protein stability in a cellular environment using E. coli as a paradigm for macromolecular crowding, because the content of macromolecules in its cell is well described. ${ }^{19,21}$ Our rapid protein-folding assay in E. coli (Figure 1) is based on the (enhanced) green fluorescent protein, EGFP. ${ }^{22}$ The target protein is fused to the $\mathrm{N}$ terminus of EGFP, which fluoresces only when the upstream target protein is expressed in a soluble form. ${ }^{23}$ We found that the rapid protein-folding assay in E. coli parallels the stability of p53 mutants in vitro, highlighting the importance of the inherent thermodynamic stability for the folding state in vivo. The results should be relevant to other proteins of similar stability expressed in E. coli.

\section{Results}

\section{The stability of p53 and its mutants correlates with fluorescence at $37^{\circ} \mathrm{C}$}

We chose wild-type p53 core domain (residues 94-312) and a set of seven mutants for which the difference in protein stability covers a range of $6 \mathrm{kcal} / \mathrm{mol}$ in vitro from the stabilized mutant T-p53C, to the highly destabilized mutant p53CV143A (Figure 2). ${ }^{31,34,35,40}$ We established whether we could detect mutation-induced stability changes using the rapid protein-folding assay based on the fluorescence of EGFP fused to p53C (Figure 1). We fused the gene of EGFP downstream to that of p53C and its mutants, separated by a short flexible linker of 16 amino acid residues, composed mainly of glycine interspersed with serine. The fusion protein was expressed in E. coli cells by induction and growth at $37^{\circ} \mathrm{C}$, and the fluorescence was measured in the living cells. No leaking of the fusion protein into the surrounding medium was detected. The normalized fluorescence value (\%RFU-EGFP), which equals the fluorescence normalized to that of EGFP expressed without being fused to p53, was calculated for the different $\mathrm{p} 53$-EGFP fusion protein constructs (see Materials and Methods). We found higher fluorescence values for the more stabilized

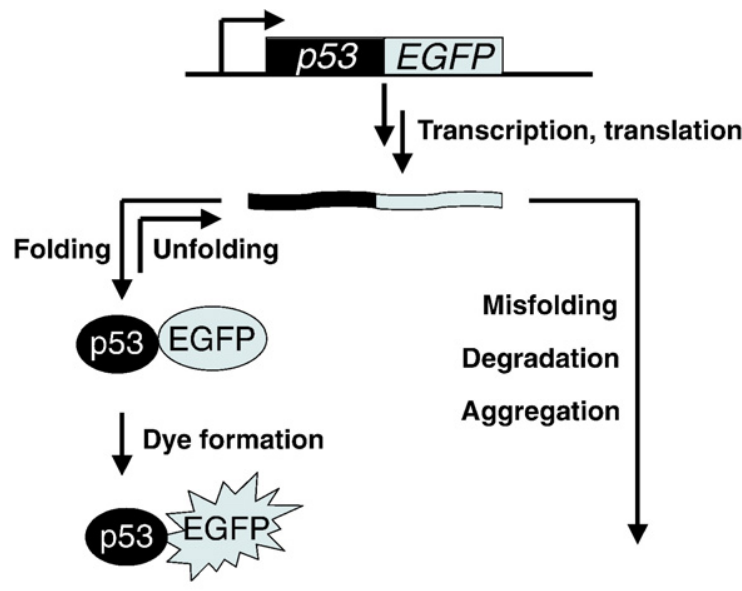

Fluorescence

No fluorescence

Figure 1. Mechanism of the rapid protein-folding assay in Escherichia coli. We used a modification of the rapid protein-folding assay first described by Waldo et al., ${ }^{22}$ in which a test protein is fused to the $\mathrm{N}$ terminus of GFP. In our system, the target protein p53C is fused to the $\mathrm{N}$ terminus of EGFP. When p53C is unfolded, it interferes with the early stage of the EGFP folding pathway, preventing EGFP from folding properly and forming a fluorescent EGFP protein. If p53C is fully folded, however, it does not interfere with the EGFP pathway and the formation of the chromophore occurs. Accordingly, the intensity of the fluorescence signal is proportional to the amount of folded target protein. For a given temperature, the amount of folded protein is determined by the thermodynamic stability of the target protein. In the in vivo assay, additional factors such as proteolysis may have an influence on the observed fluorescence signal. 


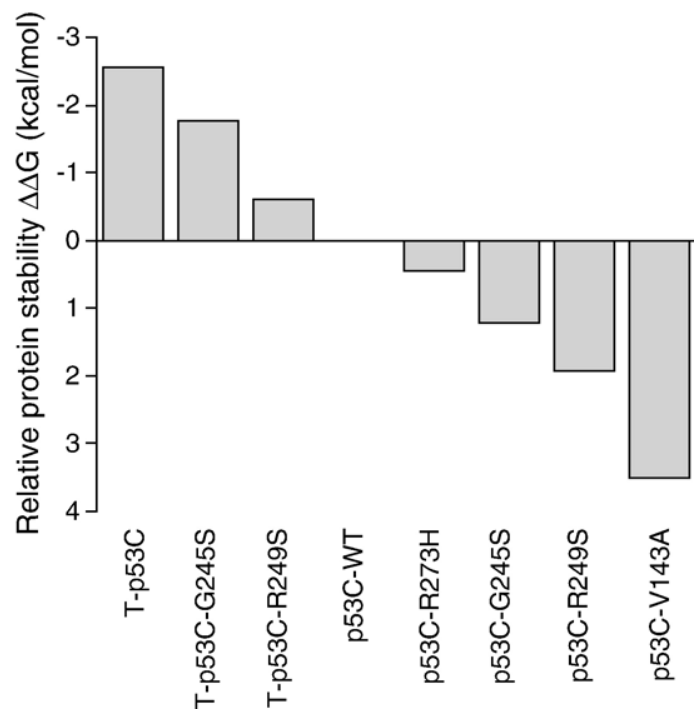

Figure 2. Relative stabilities of p53 core domain (p53C) and its mutants. Relative stabilities are given as $\Delta \Delta G$ values $(\mathrm{kcal} / \mathrm{mol}) . \Delta \Delta G$ is defined as the difference in the stability $\Delta G$ of a particular mutant and wild-type p53C, and it monitors the stability changes of p53C introduced by mutation. A stabilizing mutation results in a negative $\Delta \Delta G$ value, and a destabilizing mutation gives a positive $\Delta \Delta G$ value, whereas p53 wild-type has by definition a $\Delta \Delta G=0 . \Delta \Delta G$ values derived from urea denaturation studies for the wild-type and the various mutants were taken directly, or calculated, from published work. $31,34,35,40$

mutants relative to the destabilized mutants at a given temperature (Figure 3(a)). For example, at $37{ }^{\circ} \mathrm{C}$ the T-p53C mutant, which is stabilized by 2.5 $\mathrm{kcal} / \mathrm{mol}$, shows a fluorescence value of $48 \%$ RFUEGFP, whereas the wild-type fusion protein has a fluorescence value of 19\% RFU-EGFP. The mutant p53C-V143A, which is destabilized by $3.5 \mathrm{kcal} / \mathrm{mol}$, has the lower value of $15 \%$ RFU-EGFP. These results show that our assay can discriminate between stable and unstable p53 protein.

\section{Thermodynamic stability of the p53 core domain upon fusion to EGFP}

We monitored the thermal unfolding of wild-type p53 core domain and the corresponding EGFP fusion protein in vitro by differential scanning calorimetry to establish whether the fusion to EGFP has an effect on the thermodynamic stability of the core domain. We have found that under conditions of rapid heating, the melting temperature $\left(T_{\mathrm{m}}\right)$ for p53C is the same as that measured by true reversible denaturation procedures. ${ }^{31}$ For both isolated p53C and the p53C-EGFP fusion protein, a thermal unfolding process with an apparent $T_{\mathrm{m}}$ of $45{ }^{\circ} \mathrm{C}$ was observed, indicating that the thermodynamic stability of p53C is not affected by the fusion to EGFP (Figure 4). The fusion protein showed a second major thermal transition with an apparent $T_{\mathrm{m}}$ of $86^{\circ} \mathrm{C}$, which is in good agreement with the $T_{\mathrm{m}}$ of $83{ }^{\circ} \mathrm{C}$ for isolated EGFP determined by Nagy et al. at a similar $\mathrm{pH}$ but lower ionic strength and by applying slower heating rates. ${ }^{41}$

\section{Folding detected by fluorescence correlates with analysis by Western blots}

Thermodynamic stability changes caused by mutations have an impact on the fraction of folded protein at equilibrium. Similar levels of total protein synthesized would be expected using the same protein expression system for the different mutants in bacterial cells. But, at a given temperature, a more stable protein would exist in a higher proportion in the folded soluble fraction compared with a destabilized one. We examined, therefore, whether we could correlate the fluorescence measured in vivo with the concentration of soluble folded protein estimated by Western blot analysis.

All p53 mutants were expressed in the same vector and produced in E. coli at $37^{\circ} \mathrm{C}$. The samples were diluted to the same cell number $\left(A_{600}\right)$. We could not determine the expression levels accurately by staining with Coomassie brilliant blue because of the background of E. coli proteins. The expression levels and the soluble fractions of the fusion proteins were analysed, instead, by Western blots using an EGFP antibody (see Materials and Methods). We observed the same expression level of fusion protein for all the mutants in the whole cell fraction (Figure $3(b))$. In the soluble fraction, which was assumed to contain folded protein only, we detected a band with an apparent molecular mass of approximately $52 \mathrm{kDa}$ for p53C (Figure 3(c)), which is in good agreement with the expected mass of $53 \mathrm{kDa}$ for the fusion protein. We observed a strong band for $T$-p53C and a decrease in the band intensity of T-p53C-G245S and T-p53C-R249S. For wild-type and the other mutants, we detected almost no soluble protein. These findings show a good agreement between the measured fluorescence values in vivo and the folding state detected by Western blot analysis at $37^{\circ} \mathrm{C}$ (Figure 3).

\section{Detection of changes in folding state of p53-EGFP in vivo with temperature}

Lowering the temperature shifts the equilibrium between native and denatured states of a protein to the native state, and thus increases the amount of soluble and folded protein. We investigated whether the decrease in temperature gave an increase in fluorescence in our assay.

Cells expressing p53 fusion proteins were grown at $37{ }^{\circ} \mathrm{C}$ before induction, then shifted to various temperatures ranging from $25^{\circ} \mathrm{C}$ to $37^{\circ} \mathrm{C}$. All the fusion proteins, grown at one specific temperature, were expressed in parallel. The fluorescence value (\%RFU-EGFP) for p53C fusion protein and its mutants was measured. For T-p53C-R249S, for example, we found that a stepwise temperature decrease from $37^{\circ} \mathrm{C}$ to $25^{\circ} \mathrm{C}$ resulted in a significant increase in the fluorescence value from $30 \%$ at $37{ }^{\circ} \mathrm{C}$, to $58 \%$ 
(a)

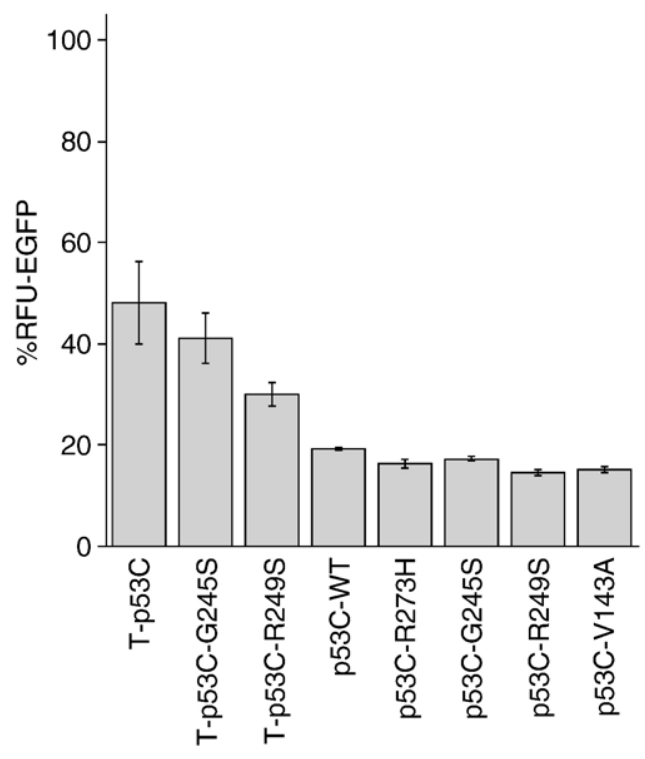

(b)

(c)
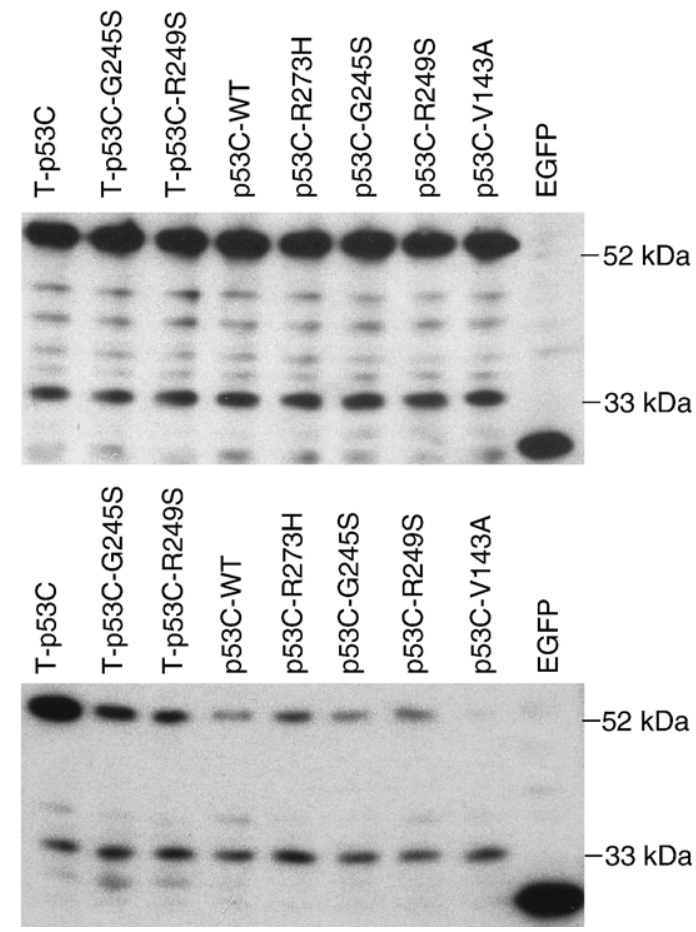

Figure 3. Fluorescence and Western blot analysis of the expression levels of p53C-EGFP fusion protein at $37^{\circ} \mathrm{C}$. (a) The folding state of p53C fused to EGFP detected in vivo by fluorescence spectroscopy. Normalized relative fluorescence units (\% RFU-EGFP) for wild-type p53 and several mutants with various thermodynamic stabilities $(\Delta \Delta G$ values; $\mathrm{kcal} / \mathrm{mol})$. (b) Expression level of the p53C-EGFP fusion protein $(53 \mathrm{kDa})$ in E. coli cells analyzed by Western blot. The whole cell fraction shows the expression level of p53C-EGFP fusion protein and its mutants, and that the total amount of expression of the soluble and insoluble fraction of the p53C fusion protein is the same. (c) Western blot analysis of the soluble fraction, which was extracted from the whole cell fraction, shows the amount of soluble p53C-fusion protein, which is dependent on its stability. From lanes T-p53C to T-p53C-R249S we can detect a decrease in the amount of soluble protein, lanes p53C to p53C-V143A have almost none.

at $33.5^{\circ} \mathrm{C}$, reaching saturation of fluorescence with a value of $74 \%$ at $30{ }^{\circ} \mathrm{C}$ and $70 \%$ RFU-EGFP at $25{ }^{\circ} \mathrm{C}$ (Figure 5(a)). We found a good correlation between fluorescence and the amount of folded protein at the different temperatures (Figure 5(a) and (b)). For example, at $33.5^{\circ} \mathrm{C}$ we measured \%RFU-EGFP values for T-p53C, T-p53C-G245S and T-p53C-R249S of $63 \%, 64 \%$ and $58 \%$, respectively, and we detected

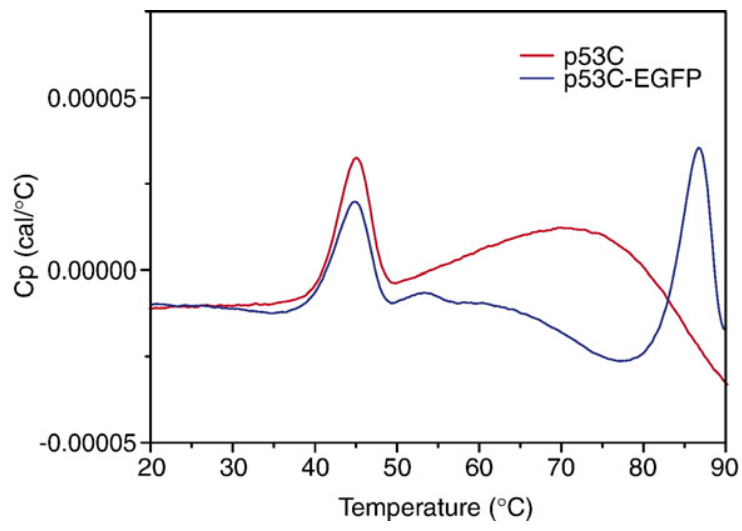

Figure 4. Thermal denaturation of isolated p53C (red line) and p53C fused to EGFP (blue line). The thermal unfolding was monitored by differential scanning calorimetry in $25 \mathrm{mM}$ phosphate buffer ( $\mathrm{pH} 7.2$ ), $150 \mathrm{mM} \mathrm{KCl}$ $5 \mathrm{mM}$ DTT at a heating rate of $250 \mathrm{deg} . \mathrm{C} / \mathrm{h}$. strong bands for T-p53C, T-p53C-G245S and a slightly weaker band for T-p53C-R249S by Western blot analysis. This fluorescence-solubility correlation was detected also at $30{ }^{\circ} \mathrm{C}$ and $25{ }^{\circ} \mathrm{C}$. The Western blot results of the soluble fraction at $33.5^{\circ} \mathrm{C}$ revealed more mutants with a strong band at $53 \mathrm{kDa}$ than those at $37^{\circ} \mathrm{C}$, showing the effect of temperature change. At $37^{\circ} \mathrm{C}$, only T-p53C showed a strong band, whereas at $33.5^{\circ} \mathrm{C} T-p 53 \mathrm{C}$ as well as T-p53C-G245S showed a strong band (Figure 5(b)). Altogether, these results show that it is possible to monitor the folding state of a p53C fusion protein in vivo at different temperatures.

\section{Aggregation, degradation and proteolysis can influence the sensitivity of the in vivo stability assay}

Denatured or misfolded protein is prone to aggregation, degradation and proteolysis. Under certain conditions, proteolytic degradation may produce stable and soluble fragments. Our Western blot analysis showed the expression level of the intact soluble p53C fusion protein, and we observed soluble degradation products with apparent molecular mass less than that of the fusion protein but greater than that of the EGFP protein alone (Figures 3(c) and 5(b)). As EGFP is known to be resistant to 


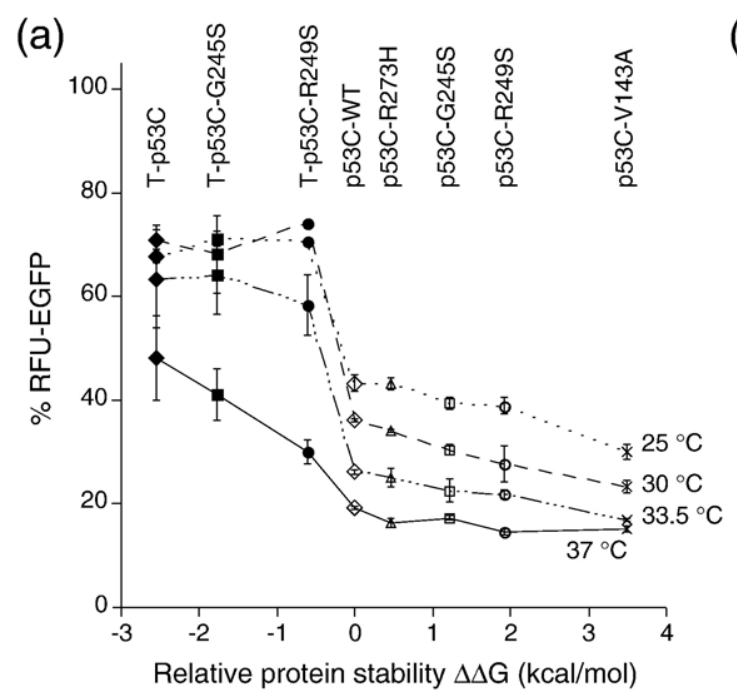

(b)

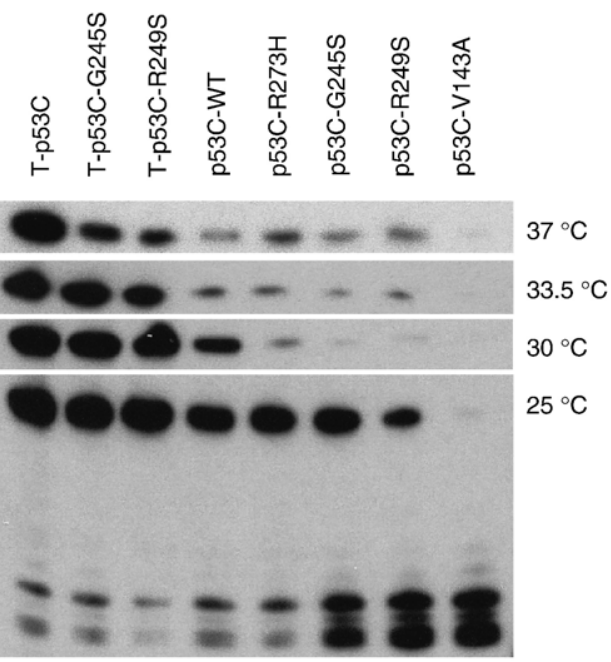

(c)

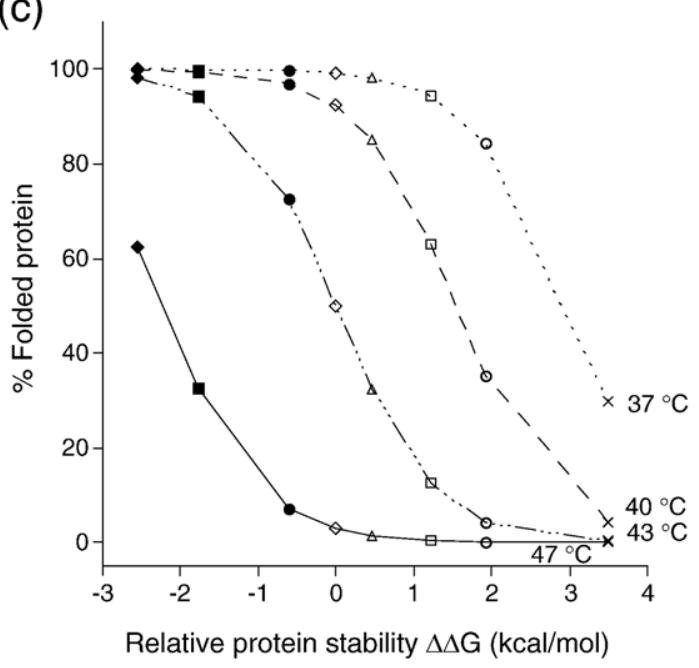

Figure 5. Folding state of p53 core domain in vivo and in vitro. (a) The folding state of the p53 core domain fused to EGFP at different temperatures detected in vivo by fluorescence spectroscopy. Normalized relative fluorescence units (\% RFU-EGFP) for p53 wild-type and various p53 mutants with various thermodynamic stabilities ( $\Delta \Delta G$ values; $\mathrm{kcal} / \mathrm{mol}$ ) at $37^{\circ} \mathrm{C}$ (continuous line), $33.5^{\circ} \mathrm{C}$ (dot-dash line), $30^{\circ} \mathrm{C}$ (broken line) and $25{ }^{\circ} \mathrm{C}$ (dotted line). The different p53 core

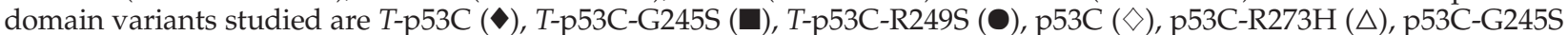
$(\square)$, p53C-R249S $(O)$ and p53C-V143A $(\times)$.The mutants are arranged in order of decreasing thermodynamic stability from T-p53C on the left to V143A on the right. (b) Soluble fraction of p53C-EGFP fusion protein and its mutants at different temperatures detected by Western blot analysis. Decreasing the temperature from $37^{\circ} \mathrm{C}$ to $25^{\circ} \mathrm{C}$ produces a dramatic increase in solubility of the p53C fusion protein and its mutants. The proteolytic activity increases from the stable mutant T-p53C to the unstable p53C-V143A as shown at $25^{\circ} \mathrm{C}$ (see the text for details). (c) The folding state of the p53C and its mutants in vitro at $47^{\circ} \mathrm{C}, 43{ }^{\circ} \mathrm{C}, 40^{\circ} \mathrm{C}$ and $37^{\circ} \mathrm{C}$. The amount of folded protein at these temperatures was calculated for

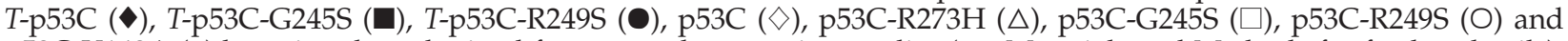
p53C-V143A $(\times)$ by using data obtained from urea-denaturation studies (see Materials and Methods for further details). The melting temperature $\left(T_{\mathrm{m}}\right)$ of p53 core domain under the experimental conditions employed was $43{ }^{\circ} \mathrm{C}$ (continuous line). At temperatures above $T_{\mathrm{m}}$, the amount of folded p53 and its mutants decreases significantly, as shown for $47^{\circ} \mathrm{C}$, and at temperatures below $T_{\mathrm{m}}$, the amount of folded p53 and its mutants increases, as shown for $40{ }^{\circ} \mathrm{C}$ and $37^{\circ} \mathrm{C}$.

many proteases, ${ }^{42}$ we hypothesized that p53C itself was cleaved by a protease, creating shortened fusion protein fragments with intact EGPF, which may also have fluorescence activity and affect the apparent magnitude of fluorescence of the intact fusion protein. The amount of the soluble proteolytic fragments correlated inversely with the stability of the p53C mutant in question: the smallest amount of fragments was observed for T-p53C and the largest amount for the highly destabilized p53C-V143A mutant (Figure $5(\mathrm{~b}), 25{ }^{\circ} \mathrm{C}$ ). Further, when the temperature was decreased, we detected an increase in shortened, soluble fragments for all mutants of p53C by Western blot (Figure $3(\mathrm{c}), 37^{\circ} \mathrm{C}$ and Figure $\left.5(\mathrm{~b}), 25{ }^{\circ} \mathrm{C}\right)$. And, because of the increase of proteolytic fragments when the temperature was lowered, we detected an increase in background fluorescence (\% RFU-EGFP) (Figure 5(a)). We conclude that at lower temperature the proteolytic intermediates were stable and soluble, and could, 
therefore, show fluorescence activity. The fluorescence arising from these intermediates might have masked differences in fluorescence for mutants with a lower level of stability than wild-type p53C (p53C-G245S, p53C-R249S and p53C-V143A) (Figure 5(a)).

\section{Full-length p53 in vivo}

Similar experiments were performed with fulllength p53 protein fused to EGFP. Consistent with earlier results for the core domain, we found higher fluorescence values when cells expressed p53-EGFP fusion protein at lower temperature. At $25^{\circ} \mathrm{C}$, wildtype p53-EGFP fusion protein produced a fluorescence value of $18 \%$ RFU-EGFP, while at $37{ }^{\circ} \mathrm{C}$, this decreased to $6 \%$ RFU-EGFP. There was, however, no detectable difference between different mutants of full-length p53 (data not shown). Western blot using EGFP antibodies showed a band for T-p53 in the soluble fraction, which agreed well with an expected mass of $72 \mathrm{kDa}$ for the fusion protein. We did not, however, detect a soluble full-length fusion product for the unstable mutant p53-V143A, but a lower molecular mass species greater in size than EGFP was observed. Again, this fragment is most likely a proteolytic product that exhibits fluorescence activity. From T-p53 to the unstable p53-V143A mutant, an increase in the amount of proteolytic fragments and a decrease in the amount of full-length protein were observed (data not shown). This trend is consistent with a seminal study on mutants of the $\lambda$ repressor, showing that thermal stability is a key determinant of the proteolytic susceptibility of this protein in E. coli. ${ }^{8}$ We could not use the fluorescencebased assay to detect stability differences of fulllength p53 because of proteolysis, and, for that reason, we conclude that this kind of stability measurement cannot be performed if the target protein is susceptible to proteolysis.

\section{Discussion}

In this study, we used a rapid folding assay with a wide range of stability mutants of p53, an important protein in the prevention of cancer development, to demonstrate the real-time effects of mutations on thermodynamic stability in vivo. The level of a protein in a cell is controlled by a number of factors and depends on the balance between rate of biosynthesis and degradation, denaturation and aggregation. Several studies on the thermodynamic stability of p53 have been done in vitro, $31,32,34$ but the effects on the folding state in vivo have not been measured. With our real-time EGFP assay, where the levels of folded p53 were measured fluorimetrically in the living cells, we were able to detect differences in thermodynamic stability at a given temperature. Even shifts in the folding state upon temperature change were monitored. Remarkably, the amount of fluorescence correlated with the thermodynamic stability of the mutant. Thermodynamic stability changes introduced by mutational changes in the protein showed similar effects on the folding state in vivo and in vitro.

\section{Comparison of protein stability in vitro and in vivo}

On the basis of the published $T_{m}$ of $43^{\circ} \mathrm{C},{ }^{34}$ we calculated the fraction folded for p53C and different mutants in a temperature range of $37^{\circ} \mathrm{C}$ to $47^{\circ} \mathrm{C}$, close to the calculated $T_{\mathrm{m}}$ of p53 core domain in vitro (Figure 5(c); see Materials and Methods for the calculation). We compared the predicted state of folding of p53C in vitro with the observed folding state of the different p53 mutants at different temperatures in vivo (relative EGFP fluorescence values; Figure 5(a)) and estimated an apparent $T_{\mathrm{m}}$ in vivo. The position of the mutant is dependent on its stability relative to wild-type, hence T-p53C, which is $2.5 \mathrm{kcal} / \mathrm{mol}$ more stable than wild-type, has a value of -2.5 on the $x$-axis and p53C-V143A which is $3.5 \mathrm{kcal} / \mathrm{mol}$ less stable than wild-type has a value of 3.5 on the $x$-axis. As expected, the observed folding state of different p53 mutants in vivo is governed by their intrinsic thermodynamic stabilities and is therefore, temperature-dependent. There were, however, systematic deviations from the theoretically expected folding states. The curves based on in vivo fluorescence data were shifted to lower temperatures compared with the calculated curve progressions based on in vitro data, indicating that the apparent $T_{\mathrm{m}}$ of the core domain in the bacterial system is lower than the value determined on the basis of urea-denaturation studies in vitro. For example, in the bacterial system, T-p53C was partially folded at $37^{\circ} \mathrm{C}$ and reached a plateau that represents the fully folded state at $33.5^{\circ} \mathrm{C}, 30{ }^{\circ} \mathrm{C}$ and $25^{\circ} \mathrm{C}$. Based on the in vitro data, however, T-p53C should be partially folded at $47^{\circ} \mathrm{C}$ and reach the plateau at $43^{\circ} \mathrm{C}$ and below (Figure 5(c)). Similarly, for T-p53CR249S the plateau is reached at $30{ }^{\circ} \mathrm{C}$ and $25^{\circ} \mathrm{C}$ in vivo, although on the basis of the in vitro data it should reach a plateau at $40{ }^{\circ} \mathrm{C}$ and lower.

When the folding state of different mutants at the same temperature was analysed, an interesting correlation between the sigmoidal experimental curves, based on in vivo data (Figure 5(a)), with the sigmoidal theoretical curves, calculated from in vitro data was observed (Figure 5(c)). For example, the fluorescence curve progression from T-p53C to p53C-V143A at $37^{\circ} \mathrm{C}$ resembled the progression of the predicted folding state curve at $47^{\circ} \mathrm{C}$. In both cases, the curves did not reach a plateau, the state where p53C is fully folded, and the decrease in folded protein or fluorescence looked similar. If the effects of proteolysis were taken into account, then there was also a clear similarity between the theoretical curve at $43{ }^{\circ} \mathrm{C}$ and the experimental curve at $33.5{ }^{\circ} \mathrm{C}$, between the theoretical curve at $40{ }^{\circ} \mathrm{C}$ and the experimental curve at $30{ }^{\circ} \mathrm{C}$, and between the theoretical curve at $37{ }^{\circ} \mathrm{C}$ and the experimental curve at $25^{\circ} \mathrm{C}$. This suggests that the system as a whole is shifted to lower temperature, 
and that the apparent melting temperature monitored in E. coli is $\sim 10$ deg.C lower than the theoretical melting temperature of $43{ }^{\circ} \mathrm{C}$ based on the in vitro data. ${ }^{34}$ Accordingly, an apparent $T_{\mathrm{m}}$ of $\sim 33^{\circ} \mathrm{C}$ was estimated for the p53C-EGFP fusion protein in this specific E. coli system. However, in the context of the cell, this is an apparent $T_{\mathrm{m}}$ and not the actual $T_{\mathrm{m}}$. The reason for the difference in apparent $T_{\mathrm{m}}$ is that a true thermodynamic equilibrium is measured in vitro but the protein is present at steadystate levels in vivo. The concentration in the cell is given by a balance between the rate of biosynthesis $\left(V_{\mathrm{f}}\right)$ and its rate of breakdown by factors such as spontaneous aggregation and proteolysis $\left(k_{\mathrm{D}}\right.$ and $\left.k_{\mathrm{P}}\right)$. The steady-state level is not the same as the thermodynamic equilibrium but clearly has a component directly related to the thermodynamic stability. The p53 steady-state level is given by the equation:

$$
[\mathrm{p} 53]_{\mathrm{ss}}=V_{\mathrm{f}} /\left(k_{\mathrm{D}}+k_{\mathrm{P}}\right)
$$

where $k_{\mathrm{D}}$ correlates with the thermodynamic equilibrium constant $K_{\text {eq }}$ as shown by Friedler et al. ${ }^{43}$ Studies of mutants of the $\lambda$ repressor show that the rate of proteolysis in E. coli is directly correlated with the thermodynamic stability of the protein. ${ }^{8}$ All in all, the results presented here show that thermodynamic stability has an important effect on the level of p53 in the cell.

In human and mouse cell lines, p53 protein levels are tightly regulated via a complex auto-regulatory network, which involves E3 ubiquitin ligases, such as HDM2/MDM2 that bind to p53 and promote its ubiquitination and subsequent degradation. ${ }^{37-39} \mathrm{E}$. coli lacks the p53-specific feedback loops that regulate cellular p53 levels in human cells lines. It is therefore ideally suited to study the effects of thermodynamic stability on the inherent folding state of mutants in the absence of specific degradation. We are currently extending our EGFP reporter system to human cell lines to study the consequences of mutation-induced changes of both stability and DNAbinding properties on the cellular protein levels.

\section{Applications of the fluorescence assay}

There are many potential applications of this bacterial assay, for example as a screening assay to test for therapeutic compounds that bind p53 in the folded state, thereby stabilizing p53 and reactivating its function. ${ }^{4}$ The assay is not restricted to p53 and could be extended to other proteins that lose their function because of reduced stability and solubility. As such, it complements the repertoire of available techniques to study protein stability in vivo, such as the real-time fluorescent labelling technique reported by Ignatova and Gierasch, ${ }^{11}$ where a biarsenical ligand was bound to an engineered tetracysteine motif in a surface loop of cellular retinoic acid-binding protein I. It could be also beneficial for the optimization of industrial production of therapeutic proteins or biocatalysts.

\section{Conclusion}

Our analysis of the effects of thermodynamic stability on the steady-state levels of p53 in living cells highlights the importance of the thermodynamic stability of a protein. The results show clearly that the level of folded protein in an organism depends on the rate of its biosynthesis and degradation, and crucially on its intrinsic thermodynamic stability. Proteins with a low intrinsic stability, such as the tumour suppressor p53, are therefore more susceptible to inactivation by mutationinduced stability changes than their more stable counterparts.

\section{Materials and Methods}

\section{Cloning the GFP folding reporter}

The p53 gene fragments for both core domain (residues 93-312) and full-length p53 were amplified by PCR from a plasmid containing wild-type p53 or its mutants using the reverse 5'-GAGCACTGCCCAACAACACCGGTACCGGTTCCGGTGGCGGTTCCGGTGG CGGTTCTGGTGGCGGTGCCATGGCATG-3' and forward 5'-GGGAATTCCATATGTCATC TTCTGTCCCTTCCC-3' oligonucleotides for the core domain, and the forward 5'GGGAATTCCATATGGAGGAGCCGCAGTCAGATC-3' and reverse $\overline{5^{\prime}-C A G A A G G G C C T G A C T C A G A C G G T A C-}$ CGGTTCCGGTGGCGGTTCCGGTGGCGGTTCTGGTGGCGGTGCCATGGCATG-3' oligonucleotides for the fulllength fragment. The amplification product contains a p53 construct with a C-terminal amino acid linker GTGS(GGGS) ${ }_{2}$ GGGAM (italics in the oligonucleotides), removes the stop codon and leaves at its $5^{\prime}$ and $3^{\prime}$ ends the recognition sequence for NdeI and NcoI, respectively (underlined in the oligonucleotides). The resulting gene fragments were digested with NdeI/NcoI, and together with NcoI/EcoRI-digested EGFP (BD Bioscience Clontech (US)), were ligated into an NdeI/ EcoRI-digested pET24a (+) vector (Novagen, Madison, WI).

\section{Fluorescence measurements and determination of folding state}

The vector expressing the fusion protein was transformed into the E. coli strain C41, ${ }^{44}$ and cultures were grown at $37{ }^{\circ} \mathrm{C}$ in $2 \times \mathrm{TY}$ medium supplemented with $40 \mathrm{mg} / 1$ of kanamycin. At $A_{600}=0.4-0.7$, the cells were induced with isopropyl- $\beta, D-$ thiogalactopyranoside (IPTG) to a final concentration of $1 \mathrm{mM}$, and growth was continued at different temperatures. The cultures were diluted $1: 17(\mathrm{v} / \mathrm{v})$ in $10 \mathrm{mM}$ Tris $-\mathrm{HCl}(\mathrm{pH}$ 7.4), $150 \mathrm{mM} \mathrm{NaCl}$. Fluorescence was measured using a 96well plate reader (Molecular Devices, SpectraMax GeminiXS) (excitation $460 \mathrm{~nm}$; emission $510 \mathrm{~nm}$; cutoff $475 \mathrm{~nm}$ and bandwidth $9 \mathrm{~nm}$ ) and 96-well plates (COSTAR ${ }^{\circledR} 3595$, Corning Incorporated USA). The cell density was normalized to $A_{600}=1$. The $A_{600}$ and EGFP normalized relative fluorescence values ( $\%$ RFU-EGFP) for each p53-EGFP fusion protein were calculated using equation (1), where $\mathrm{RFU}_{\text {(fusion protein), }} \mathrm{RFU}_{\text {(background) }}$ and $R F U_{(E G F P)}$ represent the fluorescence value for the cells expressing p53-EGFP fusion protein, the cells 
expressing p53C alone and the cells expressing EGFP, respectively:

$$
\begin{aligned}
\% R F U-E G F P= & \frac{\operatorname{RFU}_{(\text {fusion protein })}-\mathrm{RFU}_{\text {(background })}}{R F U_{(\mathrm{EGFP})}-\mathrm{RFU}_{(\text {background })}} \\
& \times 100
\end{aligned}
$$

All experiments were done in triplicate. Cells were cracked using BugBuster ${ }^{\mathrm{TM}}$ Protein Extraction Reagent (Novagen). Expression levels and the amount of soluble protein were determined by SDS-PAGE and Western blot using the GFP monoclonal antibody JL-8 (Clontech). To estimate the level of expression of the protein in the cells, the cells were diluted to $A_{600}=0.7$. A $50 \mu \mathrm{l}$ portion of BugBuster was added to $50 \mu \mathrm{l}$ of this bacterial suspension, which was incubated for $10 \mathrm{~min}$ at room temperature, and then $30 \mu \mathrm{l}$ was removed, which represents the expression level of the whole cell. To obtain the soluble fraction, the sample was centrifuged for $10 \mathrm{~min}$ (Eppendorf Centrifuge $5424 ; 13,000 \mathrm{rpm}$ ) and the supernatant analysed for the soluble fraction or folded fraction of the protein.

\section{Protein purification}

Wild-type p53 core domain was purified essentially as described, ${ }^{34}$ but with an additional gel-filtration step using a Superdex-75 column (Amersham Biosciences) in $25 \mathrm{mM}$ potassium phosphate buffer ( $\mathrm{pH} 7.2), 150 \mathrm{mM} \mathrm{KCl}, 5 \mathrm{mM}$ DTT. For purification of the p53C-EGFP fusion protein, the corresponding expression vector (see above) was transformed into $E$. coli BL21(DE3), and cultures were grown at $37^{\circ} \mathrm{C}$ in $2 \times \mathrm{TY}$ medium supplemented with kanamycin at $30 \mathrm{mg} / 1$. Protein expression was induced at $A_{600}=0.7$ by the addition of IPTG to $1 \mathrm{mM}$ final concentration, and the medium was supplemented with $100 \mu \mathrm{M}$ zinc sulfate. Cell growth was continued for $16 \mathrm{~h}$ at $20^{\circ} \mathrm{C}$. Cells were cracked using an Emulsiflex C5 high-pressure homogenizer (Glen Creston), and the soluble fraction was purified using a heparin column (HiTrap Heparin HP; GE Healthcare) followed by cation-exchange chromatography on SP Sepharose (HiTrap SP HP; GE Healthcare) at pH 5.5, and size-exclusion chromatography on a Superdex-75 column with the same buffer as that used for p53C.

\section{Differential scanning calorimetry (DSC)}

DSC experiments were done with a Microcal VPCapillary DSC instrument (Microcal, Amherst, MA) with an active cell volume of $\sim 125 \mu \mathrm{l}$. Temperatures from $10^{\circ} \mathrm{C}$ to $100{ }^{\circ} \mathrm{C}$ were scanned at a rate of $250 \mathrm{deg} . \mathrm{C} / \mathrm{h}$. The denaturation curves were measured at a protein concentration of $20 \mu \mathrm{M}$ in $25 \mathrm{mM}$ phosphate buffer ( $\mathrm{pH} 7.2)$, $150 \mathrm{mM} \mathrm{KCl}, 5 \mathrm{mM}$ DTT, and this buffer was used for baseline scans. Nitrogen gas was used to apply a pressure of 2.5 bar $\left(1 \mathrm{bar}=10^{5} \mathrm{~Pa}\right)$ to the cell. The data were analysed with ORIGIN software (Microcal).

\section{Estimating the folding state of p53 and its mutants at different temperatures using in vitro data}

The percentage of folded protein at a given temperature was calculated from equation (2), where [D] is the concentration of denatured protein and $[\mathrm{N}]$ is the concentration of folded protein:

$$
\Delta G_{T}=-R T \ln ([\mathrm{D}] /[\mathrm{N}])
$$

The free energy of unfolding $\left(\Delta G_{\mathrm{T}}\right)$ of p53C at a particular temperature was obtained by using equation
(3). Values for $\Delta C_{\mathrm{p}}=3.8 \mathrm{kcal} / \mathrm{mol}, T_{\mathrm{m}}=43^{\circ} \mathrm{C}$, and $\Delta H_{\mathrm{Tm}}=$ $169 \mathrm{kcal} / \mathrm{mol}$, were taken from Bullock et al. ${ }^{34}$

$$
\Delta G_{\mathrm{T}}=\Delta H_{\mathrm{Tm}}\left[1-\left(T / T_{\mathrm{m}}\right)\right]+\Delta C_{\mathrm{p}}\left[\left(T-T_{\mathrm{m}}\right)-T \ln \left(T / T_{\mathrm{m}}\right)\right]
$$

$$
\Delta \Delta G_{\mathrm{D}-\mathrm{N}}^{\mathrm{H}_{2} \mathrm{O}}=\Delta G_{\mathrm{T}}^{\mathrm{mut}}-\Delta G_{\mathrm{T}}^{\mathrm{wt}}
$$

$\Delta G_{\mathrm{T}}$ values for mutants were obtained by adding the known stability difference $\left(\Delta \Delta \mathrm{G}_{\mathrm{D}-\mathrm{N}}^{\mathrm{H}_{2} \mathrm{O}}\right)$ of the particular mutant and p53C (wild-type) to the $\Delta G_{\mathrm{T}}$ value of the p53C at a given temperature (cf. equation (4)). The stability differences of the mutants, $\Delta \Delta \mathrm{G}_{\mathrm{D}-\mathrm{N}}^{\mathrm{H}_{2} \mathrm{O}}$, which are to a good approximation independent of the temperature, were taken directly, or calculated, from published work. ${ }^{31,34,35,40}$

\section{Acknowledgements}

We thank Dr M. R. Fernandez-Fernandez for help and advice in molecular biological techniques and Caroline Blair for protein purification. H. C. A. was sponsored by the Singapore Agency for Science, Technology and Research (A*STAR), and S. R. by a Marie-Curie Long-Term-Fellowship of the EU. This research was supported by Cancer Research UK, the Medical Research Council, and by EC FP6 funding. This publication reflects the authors' views and not necessarily those of the EC. The Community is not liable for any use that may be made of the information.

\section{References}

1. Serrano, L., Day, A. G. \& Fersht, A. R. (1993). Stepwise mutation of barnase to binase. A procedure for engineering increased stability of proteins and an experimental analysis of the evolution of protein stability. J. Mol. Biol. 233, 305-312.

2. Meiering, E. M., Serrano, L. \& Fersht, A. R. (1992). Effect of active site residues in barnase on activity and stability. J. Mol. Biol. 225, 585-589.

3. Gething, M. J. \& Sambrook, J. (1992). Protein folding in the cell. Nature, 355, 33-45.

4. Bullock, A. N. \& Fersht, A. R. (2001). Rescuing the function of mutant p53. Nature Rev. Cancer, 1, 68-76.

5. Joerger, A. C., Ang, H. C. \& Fersht, A. R. (2006). Structural basis for understanding oncogenic p53 mutations and designing rescue drugs. Proc. Natl Acad. Sci. USA, 103, 15056-15061.

6. Canadillas, J. M., Tidow, H., Freund, S. M., Rutherford, T. J., Ang, H. C. \& Fersht, A. R. (2006). Solution structure of p53 core domain: structural basis for its instability. Proc. Natl Acad. Sci. USA, 103, 2109-2114.

7. Fersht, A. R. \& Serrano, L. (1993). Principles of protein stability derived from protein engineering experiments. Curr. Opin. Struct. Biol. 3, 75-83.

8. Parsell, D. A. \& Sauer, R. T. (1989). The structural stability of a protein is an important determinant of its proteolytic susceptibility in Escherichia coli. J. Biol. Chem. 264, 7590-7595.

9. Ghaemmaghami, S. \& Oas, T. G. (2001). Quantitative protein stability measurement in vivo. Nature Struct. Biol. 8, 879-882. 
10. Philipps, B., Hennecke, J. \& Glockshuber, R. (2003). FRET-based in vivo screening for protein folding and increased protein stability. J. Mol. Biol. 327, 239-249.

11. Ignatova, Z. \& Gierasch, L. M. (2004). Monitoring protein stability and aggregation in vivo by real-time fluorescent labeling. Proc. Natl Acad. Sci. USA, 101, 523-528.

12. Davis-Searles, P. R., Saunders, A. J., Erie, D. A., Winzor, D. J. \& Pielak, G. J. (2001). Interpreting the effects of small uncharged solutes on protein-folding equilibria. Annu. Rev. Biophys. Biomol. Struct. 30, 271-306.

13. Ellis, R. J. \& Minton, A. P. (2003). Cell biology: join the crowd. Nature, 425, 27-28.

14. Hartl, F. U. \& Hayer-Hartl, M. (2002). Molecular chaperones in the cytosol: from nascent chain to folded protein. Science, 295, 1852-1858.

15. Naylor, D. J. \& Hartl, F. U. (2001). Contribution of molecular chaperones to protein folding in the cytoplasm of prokaryotic and eukaryotic cells. Biochem. Soc. Symp. 45-68.

16. Prakash, S. \& Matouschek, A. (2004). Protein unfolding in the cell. Trends Biochem. Sci. 29, 593-600.

17. Cheung, M. S., Klimov, D. \& Thirumalai, D. (2005). Molecular crowding enhances native state stability and refolding rates of globular proteins. Proc. Natl Acad. Sci. USA, 102, 4753-4758.

18. Ellis, R. J. (2001). Macromolecular crowding: an important but neglected aspect of the intracellular environment. Curr. Opin. Struct. Biol. 11, 114-119.

19. Ellis, R. J. (2001). Macromolecular crowding: obvious but underappreciated. Trends Biochem. Sci. 26, 597-604.

20. Minton, A. P. (2000). Implications of macromolecular crowding for protein assembly. Curr. Opin. Struct. Biol. 10, 34-39.

21. Zimmerman, S. B. \& Minton, A. P. (1993). Macromolecular crowding: biochemical, biophysical, and physiological consequences. Annu. Rev. Biophys. Biomol. Struct. 22, 27-65.

22. Waldo, G. S., Standish, B. M., Berendzen, J. \& Terwilliger, T. C. (1999). Rapid protein-folding assay using green fluorescent protein. Nature Biotechnol. 17, 691-695.

23. Wang, H. \& Chong, S. (2003). Visualization of coupled protein folding and binding in bacteria and purification of the heterodimeric complex. Proc. Natl Acad. Sci. USA, 100, 478-483.

24. Vousden, K. H. \& Lu, X. (2002). Live or let die: the cell's response to p53. Nature Rev. Cancer, 2, 594-604.

25. Dawson, R., Muller, L., Dehner, A., Klein, C., Kessler, H. \& Buchner, J. (2003). The N-terminal domain of p53 is natively unfolded. J. Mol. Biol. 332, 1131-1141.

26. Cho, Y., Gorina, S., Jeffrey, P. D. \& Pavletich, N. P. (1994). Crystal structure of a p53 tumor suppressorDNA complex: understanding tumorigenic mutations. Science, 265, 346-355.

27. Jeffrey, P. D., Gorina, S. \& Pavletich, N. P. (1995). Crystal structure of the tetramerization domain of the p53 tumor suppressor at 1.7 angstroms. Science, 267, 1498-1502.

28. Bell, S., Klein, C., Muller, L., Hansen, S. \& Buchner, J. (2002). p53 contains large unstructured regions in its native state. J. Mol. Biol. 322, 917-927.
29. Joerger, A. C. \& Fersht, A. R. (2007). Structurefunction-rescue: the diverse nature of common p53 cancer mutants. Oncogene, 26, 2226-2242.

30. Roemer, L., Klein, C., Dehner, A., Kessler, H. \& Buchner, J. (2006). p53 - a natural cancer killer: structural insights and therapeutic concepts. Angew Chem. Int. Ed. Engl. 45, 6440-6460.

31. Ang, H. C., Joerger, A. C., Mayer, S. \& Fersht, A. R. (2006). Effects of common cancer mutations on stability and DNA binding of full-length p53 compared with isolated core domains. J. Biol. Chem. 281, 21934-21941.

32. Bullock, A. N., Henckel, J., DeDecker, B. S., Johnson, C. M., Nikolova, P. V., Proctor, M. R. et al. (1997). Thermodynamic stability of wild-type and mutant p53 core domain. Proc. Natl Acad. Sci. USA, 94, 14338-14342.

33. Olivier, M., Eeles, R., Hollstein, M., Khan, M. A., Harris, C. C. \& Hainaut, P. (2002). The IARC TP53 database: new online mutation analysis and recommendations to users. Hum. Mutat. 19, 607-614.

34. Bullock, A. N., Henckel, J. \& Fersht, A. R. (2000). Quantitative analysis of residual folding and DNA binding in mutant p53 core domain: definition of mutant states for rescue in cancer therapy. Oncogene, 19, 1245-1256.

35. Nikolova, P. V., Henckel, J., Lane, D. P. \& Fersht, A. R. (1998). Semirational design of active tumor suppressor 553 DNA binding domain with enhanced stability. Proc Natl Acad. Sci. USA, 95, 14675-14680.

36. Joerger, A. C., Allen, M. D. \& Fersht, A. R. (2004). Crystal structure of a superstable mutant of human p53 core domain. Insights into the mechanism of rescuing oncogenic mutations. J. Biol. Chem. 279, 1291-1296.

37. Toledo, F. \& Wahl, G. M. (2006). Regulating the p53 pathway: in vitro hypotheses, in vivo veritas. Nature Rev. Cancer, 6, 909-923.

38. Brooks, C. L. \& Gu, W. (2006). p53 ubiquitination: Mdm2 and beyond. Mol. Cell, 21, 307-315.

39. Bond, G. L., Hu, W. \& Levine, A. J. (2005). MDM2 is a central node in the p53 pathway: 12 years and counting. Curr. Cancer Drug Targets, 5, 3-8.

40. Joerger, A. C., Ang, H. C., Veprintsev, D. B., Blair, C. M. \& Fersht, A. R. (2005). Structures of p53 cancer mutants and mechanism of rescue by second-site suppressor mutations. J. Biol. Chem. 280, 16030-16037.

41. Nagy, A., Malnasi-Csizmadia, A., Somogyi, B. \& Lorinczy, D. (2004). Thermal stability of chemically denatured green fluorescent protein (GFP)- A preliminary study. Thermochim. Acta, 410, 161-163.

42. Zimmer, M. (2002). Green fluorescent protein (GFP): applications, structure, and related photophysical behavior. Chem. Rev. 102, 759-781.

43. Friedler, A., Veprintsev, D. B., Hansson, L. O. \& Fersht, A. R. (2003). Kinetic instability of p53 core domain mutants: implications for rescue by small molecules. J. Biol. Chem. 278, 24108-24112.

44. Miroux, B. \& Walker, J. E. (1996). Over-production of proteins in Escherichia coli: mutant hosts that allow synthesis of some membrane proteins and globular proteins at high levels. J. Mol. Biol. 260, 289-298.

Edited by F. Schmid 